\title{
On the possibility to accelerate the thermal isomerizations of overcrowded alkene-based rotary molecular motors with electron-donating or electron-withdrawing substituents
}

\author{
Baswanth Oruganti $^{1} \cdot$ Bo Durbeej $^{1}$ (D) \\ Received: 15 April 2016 / Accepted: 5 August 2016/Published online: 24 August 2016 \\ (C) The Author(s) 2016. This article is published with open access at Springerlink.com
}

\begin{abstract}
We employ computational methods to investigate the possibility of using electron-donating or electronwithdrawing substituents to reduce the free-energy barriers of the thermal isomerizations that limit the rotational frequencies achievable by synthetic overcrowded alkene-based molecular motors. Choosing as reference systems one of the fastest motors known to date and two variants thereof, we consider six new motors obtained by introducing electrondonating methoxy and dimethylamino or electronwithdrawing nitro and cyano substituents in conjugation with the central olefinic bond connecting the two (stator and rotator) motor halves. Performing density functional theory calculations, we then show that electron-donating (but not electronwithdrawing) groups at the stator are able to reduce the already small barriers of the reference motors by up to $18 \mathrm{~kJ}$ $\mathrm{mol}^{-1}$. This result outlines a possible strategy for improving the rotational frequencies of motors of this kind. Furthermore, exploring the origin of the catalytic effect, it is found that electron-donating groups exert a favorable steric influence on the thermal isomerizations, which is not manifested by electron-withdrawing groups. This finding suggests a new mechanism for controlling the critical steric interactions of these motors.
\end{abstract}

Keywords Electronic effects · Molecular motors · Quantum chemistry $\cdot$ Rotary rates $\cdot$ Steric effects

Electronic supplementary material The online version of this article (doi:10.1007/s00894-016-3085-y) contains supplementary material, which is available to authorized users.

Bo Durbeej

bodur@ifm.liu.se

1 Division of Theoretical Chemistry, IFM, Linköping University, SE-581 83 Linköping, Sweden

\section{Introduction}

Many of nature's complex biological tasks are carried out using molecular-sized machines oftentimes referred to as molecular motors. These molecules perform work by absorbing external energy and converting the energy into directed (i.e., non-Brownian) mechanical motion [1]. In light of their potential applications in nanotechnology [2-4], the design of synthetic molecular motors capable of mimicking their biological counterparts has been the subject of many research endeavors in recent years [5-14], alongside the development of efficient molecular switching devices [15-17]. Molecular motors that exhibit unidirectional rotary motion are commonly known as rotary molecular motors. The key characteristic of these motors is their ability to control the direction of rotation and produce rotary motion in a continuous fashion through consumption of energy.

Light constitutes a clean and readily available energy source for many different types of rotary molecular motors. The first synthetic light-driven rotary molecular motor was developed by Feringa and coworkers in the late 1990s [18, 19]. This design, which has proven particularly successful [20-37], is based on a sterically overcrowded alkene that achieves unidirectional rotary motion around a carboncarbon double bond. Examples of these motors referred to as either first-generation $[18,19,22]$ or second-generation rotary motors $[21,26,28,29,31]$ are shown in Scheme 1. All these motors, whose $360^{\circ}$ rotary cycles involve two photochemical steps and two thermal steps, have two identical or distinct halves. The "lower" half is known as the "stator", as it is immobilized on a surface in the functionalized form of the motor [35, 38-41], and the "upper" half is known as the "rotator" that rotates around the central carbon-carbon double-bond ("axle") connecting the two halves. An essential chiral feature of these motors is the helicity(ies) adopted by 


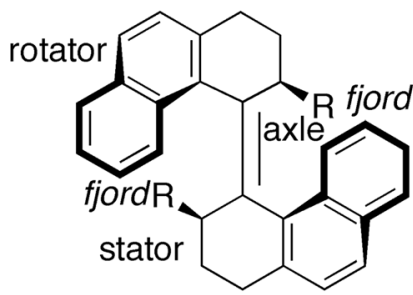

I

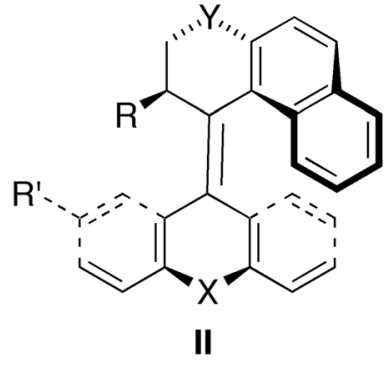

$\mathrm{X}, \mathrm{Y}=\mathrm{O}, \mathrm{S}, \mathrm{CH}_{2}$
Scheme 1 Examples of first-generation (I) and second-generation (II) light-driven overcrowded alkene-based rotary molecular motors

the motor half(ves) because of steric overcrowding in the socalled fjord regions, denoted $P$ or $M$ to indicate right-handed or left-handed helicity, respectively $[18,19]$.

First-generation motors $[18,19,22]$ employ identical stator and rotator halves and harbor two stereocenters (one on each half), whereas second-generation motors [21, 26, 28, 29, 31] contain distinct halves and a single stereocenter on the rotator. The $Z$ and $E$ isomers (with respect to the central olefinic bond) of a second-generation motor of the type ("type II") shown in Scheme 1 can exist in four conformations that differ in two ways. First, the stereogenic substituent on the rotator can adopt a favorable pseudo-axial orientation or a strained (because of steric overcrowding in the fjord regions) pseudoequatorial orientation. Conformations with these orientations are henceforth labeled "stable" and "unstable", respectively. Second, the folding of the stator and rotator relative to the plane containing the central olefinic bond and the stereocenter (hereafter referred to as the olefinic plane) can be such that the stator and rotator point toward the same side or toward opposite sides of this plane. The former conformations are henceforth labeled "syn-folded" and the latter, which exhibit less steric overcrowding in the fjord regions and therefore lie lower in energy, are labeled "anti-folded".

In a recent computational study, the relative stabilities of the four different conformations and their potential roles in the rotary cycle of a slightly modified second-generation type II motor combining a thioxanthene stator with a cyclopenta[a]napthalenylidene rotator were assessed using density functional theory (DFT) methods [42]. This motor, hereafter referred to as motor 1a, is shown in Scheme 2, together with the rotary cycle predicted by these calculations [42]. Notably, because of the small free-energy barriers of its thermal steps, it has been estimated experimentally that motor 1a should be able to achieve $\mathrm{MHz}$ rotational frequencies under suitable irradiation conditions [28].

As can be seen from Scheme 2, the rotary cycle of motor 1a comprises two photoisomerizations $(E \rightarrow Z$ and $Z \rightarrow E$ ) of an anti-folded stable isomer to produce a strained syn-folded unstable isomer, and two thermal isomerizations that release the strain to regain the anti-folded stable isomers. Further, each process occurs with a $M \rightarrow P$ or $P \rightarrow M$ change in the helicity of the rotator. Overall, the rotary cycle is governed by steric interactions in the fjord regions, which ensure that the photoisomerizations are unidirectional and the thermal isomerizations spontaneous.
Scheme 2 Overall rotary cycle of molecular motor 1a<smiles>COc1ccc2c(c1)C(=C1c3ccccc3Sc3ccc4c(c31)CCC4[14CH3])c1ccccc1-2</smiles>

anti-(M)-stable- $E$

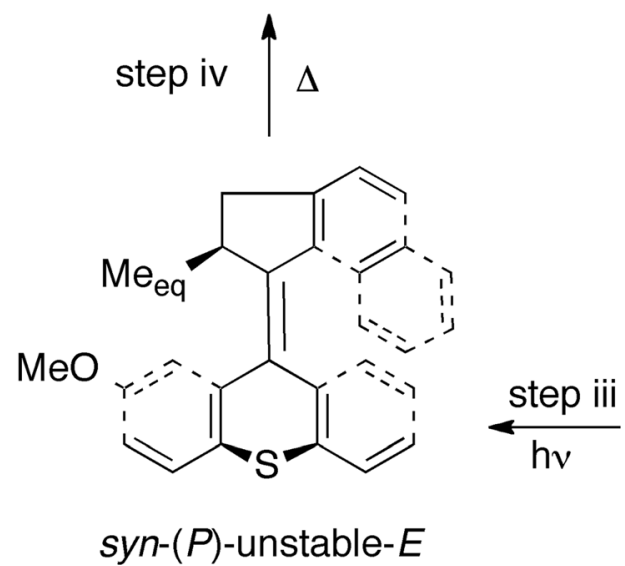<smiles>CCc1cccc2c1/C(=C1\c3cc(OC)ccc3CC1C)c1ccccc1[S-]2</smiles>

syn- $(P)$-unstable- $Z$<smiles>COc1ccc2c(c1)C(=C1c3ccccc3Sc3ccc4c(c31)C(C(C)C)CC4)c1ccccc1S2</smiles>

anti-(M)-stable- $Z$ 
To date, a variety of interesting applications of synthetic rotary molecular motors have been reported [43-46], such as in molecular transport [44] and in viscosity sensing [45, 46]. A key requirement for such applications is that the motors are able to reach high rotational frequencies under ambient conditions [27, 47]. Therefore, besides trying to usefully exploit the rotary motion of overcrowded alkenes, a major experimental effort has also been invested in exploring ways to improve the thermal isomerization rates of these motors [21, 22, 24, 26-28, 30, 31, 36], which are believed to be the limiting factor for the rotational frequencies that they can attain [28, 48, 49]. This work, of which motor $\mathbf{1 a}$ is one of the most important achievements [28], has been done by tailoring the conformational, steric, and electronic properties of the motors [21, 22, 24, 26-28, 30, 31, 36].

As a very valuable complement to these experimental efforts, a number of computational studies have been performed to investigate the mechanisms of both the photoisomerizations [50-55] and the thermal isomerizations [29, 50, 56-58] of overcrowded alkene-based motors, or to suggest alternative motor designs [59-65], including systems whose photochemical steps may be particularly efficient [65] or whose rotary cycles may consist of photochemical steps only [63, 64]. Although the thermal isomerization mechanisms of both first and second-generation motors have been explored using semiempirical [50, 56], DFT [29, 58], and Monte Carlo-like methods [57], until recently, there had been no systematic quantum chemical study of ways to lower the thermal freeenergy barriers of overcrowded alkene-based motors. Therefore, we decided to take a first step toward filling this gap by investigating the possibility to accelerate the thermal isomerizations of motor $\mathbf{1 a}$ through modulation of steric interactions $[42,66]$.

Using DFT methods and replacing the stator methoxy and rotator methyl substituents of motor 1a with groups of varying steric bulkiness, ranging from hydroxyl to tert-butyl, what we found is that the thermal free-energy barriers of motor 1a can be lowered by a substantial $15-17 \mathrm{~kJ} \mathrm{~mol}^{-1}$ if the steric bulkiness of the rotator substituent is made optimal [42]. Thus, this result identifies a possible route for improving the rotational frequencies of overcrowded alkene-based motors. For the stator substituent, on the other hand, it was found that its steric bulkiness exerts virtually no influence on the thermal rates [42].

As a natural continuation of our previous studies [42, 66], the present work uses DFT methods to systematically investigate whether the thermal isomerizations of motor $\mathbf{1 a}$, one of the fastest motors known to date [28], can also be accelerated by appropriately substituting the thioxanthene stator. Having documented that steric bulkiness is a relevant optimization target only for the stereogenic rotator substituent [42], this is done by evaluating the effects of electron-donating and electron-withdrawing stator substituents on the thermal rates of motor 1a and different variants thereof. As such, our work is related to experimental studies that have explored how the thermal rates of other second-generation motors are affected by electron-donating and electron-withdrawing substituents $[24,31]$. Interestingly, it is found that the thermal freeenergy barriers of the reference motors (motor 1a and its variants) can be lowered by up to $18 \mathrm{~kJ} \mathrm{~mol}^{-1}$ by electrondonating stator substituents. Accordingly, this finding suggests an approach for improving the rotational frequencies of overcrowded alkene-based motors that is complementary to the approach based on optimization of the steric bulkiness of the rotator substituent [42].

\section{Methods}

\section{Motors considered in this work}

Three different motors were used as reference motors for evaluating the effects of electron-donating and electronwithdrawing stator substituents on the thermal isomerization rates. Specifically, besides motor $\mathbf{1 a}$, motors $\mathbf{1 b}$ and $\mathbf{1 c}$ (see Scheme 3) were also used for this purpose. Both of the latter motors, in which the rotator methyl substituent of motor $\mathbf{1 a}$ is replaced by a nitro (motor $\mathbf{1 b}$ ) or methoxy (motor 1c) group, are examples of motors where the steric bulkiness of the rotator substituent is such that the thermal free-energy barriers are smaller than those of motor 1a (e.g., the barriers of motor 1c are $15 \mathrm{~kJ} \mathrm{~mol}^{-1}$ smaller) [42]. In this way, the calculations will probe whether it is possible to accelerate motor 1a on steric
Scheme 3 Potential light-driven rotary molecular motors $\mathbf{1 a}-\mathbf{3 c}$

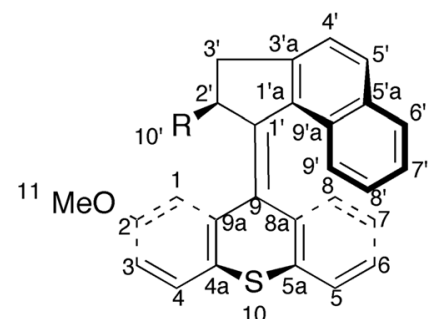

1a: $\mathrm{R}=\mathrm{Me}$

1b: $\mathrm{R}=\mathrm{NO}_{2}$

1c: $\mathrm{R}=\mathrm{OMe}$

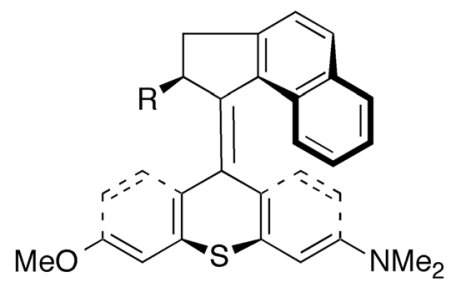

2a: $\mathrm{R}=\mathrm{Me}$

2b: $\mathrm{R}=\mathrm{NO}_{2}$

2c: $\mathrm{R}=\mathrm{OMe}$<smiles>[R7]C1Cc2ccc3ccccc3c2/C1=C1\c2ccc(C#N)cc2Sc2cc([N+](=O)[O-])ccc21</smiles>

3a: $\mathrm{R}=\mathrm{Me}$

3b: $\mathrm{R}=\mathrm{NO}_{2}$

3c: $\mathrm{R}=\mathrm{OMe}$ 
(via rotator substitution) and electronic (via stator substitution) grounds simultaneously.

Six new potential light-driven rotary motors (see Scheme 3) were derived from motors $\mathbf{1 a}-\mathbf{1 c}$ by introducing electron-donating methoxy and dimethylamino stator substituents to obtain motors $\mathbf{2 a - 2 c}$, and by introducing electronwithdrawing nitro and cyano stator substituents to obtain motors 3a-3c. The substituents, all of which are commonly employed in overcrowded alkene-based motors [23, 24, 31], were placed in direct conjugation with the central olefinic bond at the $\mathrm{C} 3$ and $\mathrm{C} 6$ positions of the thioxanthene stator. At the same time, the original methoxy substituent at the C2 position of motors $\mathbf{1 a}-\mathbf{1 c}$ was removed.

\section{Computational details}

Previously, we have found that the calculated thermal freeenergy barriers of reference motor $1 \mathbf{a}$ and several variants thereof are not at all sensitive to the choice of density functional and basis set in the modeling [42]. For example, testing five different functionals (the B3LYP [67, 68], PBE0 [69, 70] and M06-2X [71, 72] global hybrid functionals and the $\omega B 97 X-D$ [73] and CAM-B3LYP [74] range-separated hybrid functionals) and three different basis sets (the double- $\xi$, SVP basis set, the diffuse-function-containing 6-31++G(d,p) basis set, and the correlation-consistent triple- $\xi$ cc-pVTZ basis set), the maximum variation between different levels of theory as to their estimates of the thermal barriers of motor 1a is not significant [42]. Therefore, it was decided to use $\omega B$ 97X-D/ SVP as the primary level of theory in this work, in combination with the SMD continuum solvation model [75] to describe the dichloromethane solvent used in the experimental reference study of motor 1a [28]. For motor 1a, such calculations [42] yield thermal barriers that agree very well with the kinetic data reported in that study [28].

One particular reason why $\omega \mathrm{B} 97 \mathrm{X}-\mathrm{D}$ is a sound choice of method for the modeling is that it includes empirical atomatom dispersion corrections [76, 77] that are likely to offer a better description of intramolecular interactions between the stator and rotator than most other functionals. The merits of $\omega B 97 X-D$ in organocatalytic modeling have also been established in an extensive benchmark study by Clark and co-workers [78].

Using $\omega$ B97X-D/SVP in combination with the SMD mod$\mathrm{el}$, the thermal isomerizations of the motors were explored by performing geometry optimizations to locate firstly the anti-( $M)$-stable- $E$ and anti-( $M)$-stable- $Z$ light-absorbing isomers and the $s y n-(P)$-unstable- $Z$ and $s y n-(P)$-unstable- $E$ photoproduct isomers, and secondly all transition structures (TSs) and intermediates connecting these species. For the resulting geometries, frequency calculations were then performed to obtain Gibbs free energies at room temperature, and to ensure that these structures have either zero (for potential-energy minima) or one (for TSs) vibrational normal mode with an imaginary frequency. Finally, intrinsic reaction coordinate (IRC) [79] calculations were carried out to verify that the TSs found do indeed connect the associated reactant and product species.

All calculations were performed with the Gaussian 09 suite of programs [80].

\section{Results and discussion}

\section{Mechanism for the thermal isomerizations}

Through the calculations, the three-step mechanism for the thermal syn- $(P)$-unstable- $Z \rightarrow$ anti- $(M)$-stable- $Z$ and $s y n-(P)$ unstable- $E \rightarrow$ anti-(M)-stable- $E$ isomerizations of motor 1a that we proposed in an earlier computational study [42] was found to also apply to the substituted motor variants investigated in this work. Briefly, as shown in Fig. 1, the first two steps (via TS1/TS4 and TS2/TS5, respectively) of this mechanism involves a $P \rightarrow M$ change in the helicity of the rotator that shifts the orientation of the stereogenic substituent (meth$\mathrm{yl}$ in the case of motors $\mathbf{1 a - 3 a )}$ from pseudo-equatorial to pseudo-axial. Then, during the third step (via TS3/TS6), the stator undergoes a ring flip relative to the olefinic plane that changes the stator-rotator folding from syn to anti.

As can be seen from Fig. 1, all three steps of motor 1a, which is one of the three reference motors for the present calculations (the other two being motors $\mathbf{1 b}$ and $\mathbf{1 c}$, see Scheme 3), are exergonic and proceed with a net driving "force" of close to $50 \mathrm{~kJ} \mathrm{~mol}^{-1}$. Notably, the third step is the rate-determining one, with a free-energy barrier of 40-43 kJ $\mathrm{mol}^{-1}$. Now, we turn to investigating how this scenario changes when electron-donating and electron-withdrawing stator substituents are introduced in motors $\mathbf{2 a - 2 c}$ and motors $\mathbf{3 a}-\mathbf{3 c}$, respectively.

\section{Effects of electron-donating and electron-withdrawing stator substituents}

As outlined in the Introduction, the electron-donating methoxy and dimethylamino stator substituents of motors $\mathbf{2 a - 2} \mathbf{c}$ and the electron-withdrawing nitro and cyano stator substituents of motors $\mathbf{3 a}-\mathbf{3 c}$ were placed in direct conjugation with the central olefinic bond at the $\mathrm{C} 3$ and $\mathrm{C} 6$ positions of the thioxanthene. At these positions, it can be envisioned that the electron-donating or electron-withdrawing capability of the substituents will tend to elongate the olefinic bond by resonance stabilization [24], as shown in Scheme 4. If indeed present, this effect would distance the stator from the rotator and thus reduce the steric interactions in the fjord regions [24]. Furthermore, it also seems possible that such resonance stabilization would be more likely in TS1/TS4 and TS3/TS6, in which the stator is nearly planar, than in the 

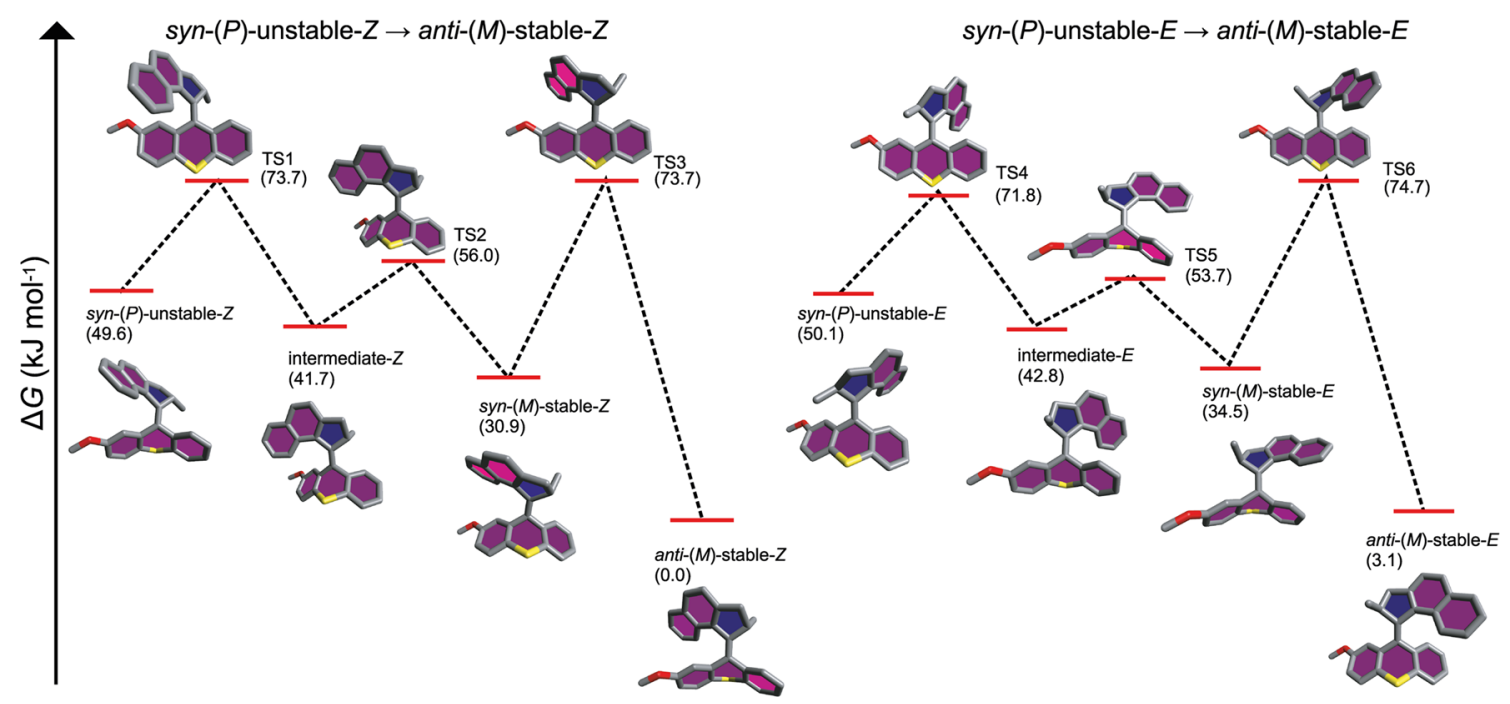

Fig. 1 Three-step mechanism for the thermal syn- $(P)$-unstable- $Z \rightarrow$ anti$(M)$-stable- $Z$ and syn- $(P)$-unstable- $E \rightarrow$ anti-( $(M)$-stable- $E$ isomerizations of motor 1a with relative free energies of stationary points given in

parentheses (the absolute configurations of the stereocenter in all isomers are given in Table S1 of the Electronic supplementary material $(\mathrm{ESM}))$

associated syn-(P)-unstable-Z/E and syn-( $M)$-stable-Z/E reactant species, in which the stator is distinctly folded relative to the olefinic plane (see Fig. 1). Thereby, the reduction in fjord-region steric interactions would be more pronounced in the transition structures, which would lower the TS1/TS4 and TS3/TS6 barriers of motors $\mathbf{2 a}-\mathbf{2 c}$ and $\mathbf{3 a}-\mathbf{3} \mathbf{c}$ relative to their values in motors $\mathbf{1 a}-\mathbf{1 c}$.

From this discussion, it is of interest to assess whether the olefinic bond is indeed longer in the stator-substituted motors $\mathbf{2 a}-\mathbf{2} \mathbf{c}$ and $\mathbf{3 a}-\mathbf{3 c}$ than in motors $\mathbf{1 a}-\mathbf{1 c}$ used as reference systems. This is done in Table S2 of the ESM, which summarizes the olefinic bond lengths in TS1/TS4 and TS3/TS6 and the preceding reactant species for all of motors $1 \mathbf{a}-\mathbf{3 c}$. However, as can be seen, for any given stationary point (reactant species or TS) the bond lengths of motors $\mathbf{2 x}$ and $\mathbf{3 x}$ are consistently almost identical (to within $0.014 \AA$ ) to those of motors $1 \mathbf{x}(\mathbf{x}=\{\mathbf{a}, \mathbf{b}, \mathbf{c}\})$. Thus, neither electron-donating nor electron-withdrawing stator substituents seem capable of elongating this bond. This result suggests that the thermal free-energy barriers of motors $\mathbf{2} \mathbf{x}$ and $\mathbf{3 x}$ ought to be similar to those of motors 1x. Interestingly, however, Fig. 2 shows that this supposition is not correct.

Specifically, Fig. 2 shows the magnitudes (denoted $\Delta \Delta G^{\ddagger}$ ) of the TS1-TS6 barriers of motors $\mathbf{2} \mathbf{x}$ and $\mathbf{3} \mathbf{x}$ relative to the corresponding barriers of motors $\mathbf{1 x}$ (motor $\mathbf{1 a}$ is the reference for motors $\mathbf{2 a}$ and $\mathbf{3 a}$, and so on). Accordingly, a negative (positive) $\Delta \Delta G^{\ddagger}$ value means that the barrier in question is lowered (increased) with respect to the reference motor. As for the actual values of all the barriers, they are given in Table S3 of the ESM.

Starting with motors $\mathbf{2 x}$ substituted with electron-donating methoxy and dimethylamino groups and focusing initially on
Scheme 4 Possible resonanceinduced elongation of the central olefinic bond of motors $\mathbf{2 a - 2 c}$ and $\mathbf{3 a}-\mathbf{3 c}$

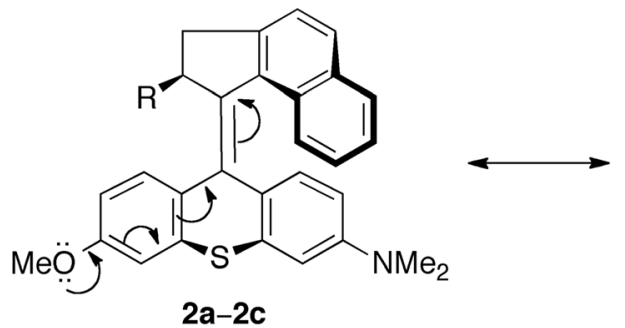

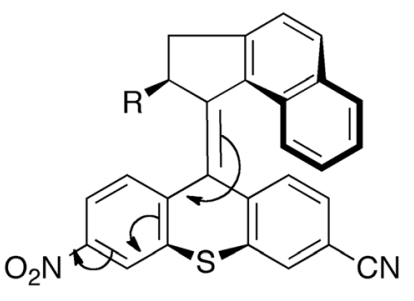<smiles>CCCCC</smiles><smiles></smiles><smiles>[R]C1Cc2ccc3ccccc3c2[C+]1c1c2ccc(=[N+]([O-])[O-])cc-2sc2cc(C#N)ccc12</smiles>

$3 a-3 c$ 
Fig. 2 Thermal free-energy barriers for motors $\mathbf{2} \mathbf{x}$ and $\mathbf{3 x}$ relative to those for motors $\mathbf{1} \mathbf{x}$

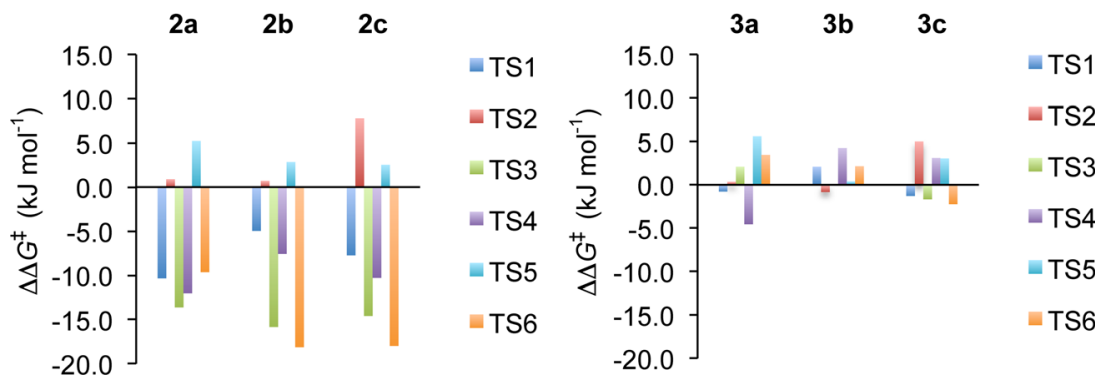

motors $\mathbf{2} \mathbf{a}$ and $\mathbf{2 b}$, Fig. 2 shows that the TS3/TS6 barriers (that are rate-determining for motors $\mathbf{1 a}$ and $\mathbf{1 b})$ are $10-18 \mathrm{~kJ} \mathrm{~mol}^{-1}$ smaller in motors $\mathbf{2 a}$ and $\mathbf{2 b}$. Also, the TS1/TS4 barriers are $5-12 \mathrm{~kJ} \mathrm{~mol}^{-1}$ smaller in these systems, whereas the TS2/TS5 barriers are roughly the same (to within $5 \mathrm{~kJ} \mathrm{~mol}^{-1}$ ) as in motors 1a and 1b. Despite these changes, the TS3/TS6 barriers remain the rate-determining ones also for motors $\mathbf{2} \mathbf{a}$ and $2 \mathbf{b}$.

Overall, as can be seen from Table S3, all six thermal barriers of motors $\mathbf{2 a}$ and $\mathbf{2 b}$ are small, ranging from 10 to $31 \mathrm{~kJ}$ $\mathrm{mol}^{-1}$ for motor $\mathbf{2 a}$, and from 7 to $23 \mathrm{~kJ} \mathrm{~mol}^{-1}$ for motor $\mathbf{2 b}$. Since the estimated rate-determining barriers of the reference motors $\mathbf{1 a}$ and $\mathbf{1 b}$ amount to 43 and $39 \mathrm{~kJ} \mathrm{~mol}^{-1}$, respectively, the calculations predict that introducing electron-donating stator substituents in conjugation with the olefinic bond can lower the rate-determining barrier by a substantial $12-16 \mathrm{~kJ}$ $\mathrm{mol}^{-1}$, from 43 (motor 1a) to $31 \mathrm{~kJ} \mathrm{~mol}^{-1}$ in motor $\mathbf{2 a}$, and from 39 (motor $\mathbf{1 b}$ ) to $23 \mathrm{~kJ} \mathrm{~mol}^{-1}$ in motor $\mathbf{2 b}$. This finding indicates that such substituents are worthwhile to consider in future attempts to improve the rotational frequencies of overcrowded alkene-based motors.

Continuing with motor 2c, Fig. 2 shows that the changes in the thermal barriers with respect to motor $1 \mathrm{c}$ are quite similar to the situation for motors $\mathbf{2} \mathbf{a}$ and $\mathbf{2 b}$ relative to their reference systems. For example, the TS3/TS6 barriers (that are ratedetermining for motor 1c) are lowered by $15-18 \mathrm{~kJ} \mathrm{~mol}^{-1}$ in motor 2c. Similarly, the TS1/TS4 barriers are also smaller, by 8-10 $\mathrm{kJ} \mathrm{mol}^{-1}$, whereas the TS2/TS5 barriers are somewhat larger, by 3-8 $\mathrm{kJ} \mathrm{mol}^{-1}$. As a result of these changes, it is the TS2/TS5 barriers that are rate-determining for motor $\mathbf{2 c}$. Nonetheless, Table S3 reveals that all six barriers of motor 2c are small, ranging from 8 to $25 \mathrm{~kJ} \mathrm{~mol}^{-1}$, which suggests that this system is also a promising candidate to achieve high rotational frequencies.

Notably, the rate-determining TS2/TS5 barriers of motor 2c are almost identical $\left(23-25 \mathrm{~kJ} \mathrm{~mol}^{-1}\right)$ to the rate-determining TS3/TS6 barriers of motor 1c (26-28 $\left.\mathrm{kJ} \mathrm{mol}^{-1}\right)$. Given that motor $\mathbf{1 c}$ is an example of a motor that is accelerated by some $15 \mathrm{~kJ} \mathrm{~mol}^{-1}$ over motor $1 \mathrm{a}$ by optimization of the steric bulkiness of the stereogenic rotator substituent [42], this observation suggests that further acceleration by simultaneous optimization of the electronic character of the stator substituent is difficult to achieve.
As for motors $\mathbf{3 x}$, finally, it can be seen from Fig. 2 that introducing electron-withdrawing nitro and cyano stator substituents does not appear a viable approach for lowering the thermal barriers relative to motors 1x. In fact, for each of motors $3 \mathbf{x}$, all six barriers have $\Delta \Delta G^{\ddagger}$ values of the order of a few $\mathrm{kJ} \mathrm{mol}^{-1}$ only.

\section{Origin of rate acceleration by electron-donating stator substituents}

Having found that electron-donating stator substituents are able to accelerate the thermal isomerizations of overcrowded alkene-based motors, as can be inferred particularly from the $12-16 \mathrm{~kJ} \mathrm{~mol}^{-1}$ catalytic effect that such substituents have on the rate-determining third step of the isomerizations of motors $\mathbf{1 a}$ and $\mathbf{1 b}$, it is of course of interest to understand why this is so. Especially, it is desirable to establish why electrondonating stator substituents (in motors $2 \mathbf{x}$ ), but not electronwithdrawing ones (in motors $\mathbf{3 x}$ ), have this ability. Before such an assessment, however, we will first investigate if the thermal barriers of motors $\mathbf{2 x}$ can be lowered even further by combining their electron-donating methyl and dimethylamino stator substituents with an electron-withdrawing rotator substituent. Tentatively, this could lengthen the olefinic bond by introducing a stator-rotator push-pull effect. To this end, a nitro group was added to the $\mathrm{C} 5^{\prime}$ position, in conjugation with the olefinic bond, of motors $2 \mathbf{x}$ to obtain motors $\mathbf{4 x}$ shown in Scheme 5. Then, the thermal isomerizations of the resulting motors were explored in the same way as the other motors, thereby also documenting a three-step mechanism for these systems. The results of the calculations are included in Tables S2 and S3.

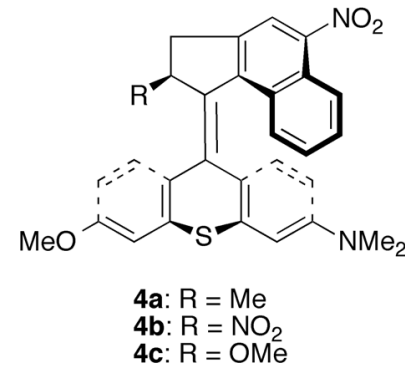

Scheme 5 Potential light-driven rotary molecular motors $4 a-4 c$ 
From Table S2, we first note that the olefinic bond lengths are essentially identical (to within $0.007 \AA$ ) in motors $\mathbf{2 x}$ and $\mathbf{4 x}$, without any sign of a geometric push-pull effect. From Table S3, in turn, we can also conclude that there is no catalytic push-pull effect on the thermal isomerization barriers. These results are consistent with the experimental observation that the electronic features of the rotator substituent have a minor influence on the thermal isomerization rates of a second-generation motor with a fluorenyl stator and a cyclopenta[a]napthalenylidene rotator [31].

Returning to the origin of the rate acceleration by electrondonating stator substituents, it is now clear that the effect is not based on elongation of the olefinic bond through resonance stabilization. As an alternative explanation, it is natural to expect that some specific features of TS3 and TS6 play a role, because it is the corresponding barriers that show by far the greatest sensitivity toward electron-donating stator substituents. Indeed, as noted in Fig. 2, these barriers are up to $18 \mathrm{~kJ} \mathrm{~mol}^{-1}$ smaller in motors $\mathbf{2 x}$ than in motors 1x. Particularly, it is sensible to explore whether electron-donating and electron-withdrawing stator substituents affect the fjord-region steric interactions in TS3 and TS6 differently. This follows directly from the discovery, in our recent study focusing on the role of steric bulkiness of the rotator substituent, of a clear correlation between the TS3 and TS6 free-energy barriers and the changes in fjord-region steric interactions in TS3 and TS6 relative to the preceding $\operatorname{syn}$ - $(M)$ stable- $Z$ and $s y n-(M)$-stable- $E$ reactant species [42].

To estimate the fjord-region steric interactions in TS3 and TS6 and the associated reactant species of motors $\mathbf{2} \mathbf{x}$ (with electron-donating stator substituents) and $\mathbf{3 x}$ (with electronwithdrawing stator substituents), we proceeded as follows. First, a simple geometric measure $S_{\mathrm{XY}}$ of these interactions in the different species was obtained by considering each atom of the rotator residing within the nominal van der Waals distance [81] of any atom of the stator. For each such interaction, the strength of the interaction was attributed a value $s_{X Y}$ equalling the magnitude by which the interatomic distance is shorter than the corresponding van der Waals distance. Then, for each structure in question, the associated $S_{\mathrm{XY}}$ value was obtained by simply summing all $s_{\mathrm{XY}}$ values. Finally, the differences $\Delta S_{\mathrm{XY}}$ between the $S_{\mathrm{XY}}$ values for TS3 and syn-(M)-stable- $Z$, and for TS6 and syn-( $M)$-stable- $E$, were computed. These values can be thought of as measures of the "steric barriers" for the processes in question.

Table S4 of the ESM lists the $S_{\mathrm{XY}}$ and $\Delta S_{\mathrm{XY}}$ values obtained for all of motors $1 \mathbf{x}-\mathbf{3 x}$. Furthermore, to evaluate how the $\Delta S_{\mathrm{XY}}$ values for motors $\mathbf{2} \mathbf{x}$ and $\mathbf{3} \mathbf{x}$ compare with those for reference motors $\mathbf{1} \mathbf{x}$, the corresponding $\Delta \Delta S_{\mathrm{XY}}$ differences between motors $\mathbf{2 x} / \mathbf{3} \mathbf{x}$ and motors $1 \mathbf{x}$ are also included. Figure 3, in turn, plots the $\Delta \Delta G^{\ddagger}$ values for TS3 and TS6 of motors $2 \mathrm{x}$ and $3 \mathbf{x}$ as a function of the $\Delta \Delta S_{\mathrm{XY}}$ values.

Notably, motors $3 \mathbf{x}$, whose thermal barriers are close to those of motors $1 \mathbf{x}$ and hence have $\Delta \Delta G^{\ddagger}$ values close to

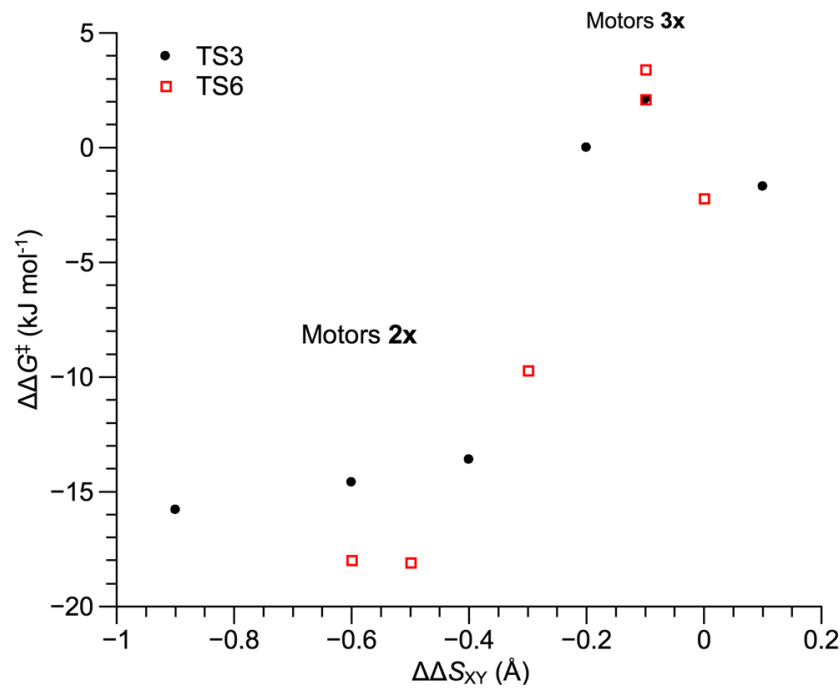

Fig. $3 \Delta \Delta G^{\ddagger}$ values for TS3 and TS6 of motors $\mathbf{2} \mathbf{x}$ and $\mathbf{3} \mathbf{x}$ as a function of the corresponding $\Delta \Delta S_{\mathrm{XY}}$ values

zero, show $\Delta \Delta S_{\mathrm{XY}}$ values that are also close to zero, which indicates that the steric requirements to pass through TS3 and TS6 are similar in motors $\mathbf{1 x}$ and $\mathbf{3 x}$. Motors $\mathbf{2 x}$, on the other hand, have thermal barriers that are up to $18 \mathrm{~kJ} \mathrm{~mol}^{-1}$ smaller than those of motors $\mathbf{1} \mathbf{x}$, and show $\Delta \Delta S_{\mathrm{XY}}$ values that are distinctly negative. This observation clearly suggests that our finding that electron-donating stator substituents are able to accelerate the thermal isomerizations of overcrowded alkene-based motors can be explained in terms of a favorable steric effect from such substituents. Thus, having previously found that modulating the steric bulkiness of the rotator substituent is a viable approach for lowering the rate-determining barriers of the thermal isomerizations, and that this strategy is not applicable to the stator substituent [42], the present data predict that it is nonetheless possible to exert a catalyzing steric influence on the thermal isomerizations from the electronic character rather than bulkiness of the stator substituents.

Clearly, it is of interest to understand why electrondonating stator substituents have a favorable steric effect on the thermal barriers, whereas electron-withdrawing ones do not. For example, comparing motor $\mathbf{2 c}$ and motor $\mathbf{3 c}$, the $S_{\mathrm{XY}}$ values in Table $\mathrm{S} 4$ reveal that the $s y n-(M)$-stable- $Z$ and syn-(M)-stable- $E$ reactant species of motor $2 \mathbf{c}$ have larger fjord-region steric interactions than the reactant species of motor 1c, which is not the case for motor 3c. Accordingly, the reactant species of motor $\mathbf{2 c}$ are de-stabilized with respect to motor 1c, which means that the TS3 and TS6 barriers are lowered. Pleasingly, this difference between motors $\mathbf{2 c}$ and $\mathbf{3 c}$ can be rationalized by noting that the electron-donating dimethylamino group of motor $\mathbf{2 c}$ extends the stator conjugation, whereas the electron-withdrawing nitro group of motor $\mathbf{3 c}$ affords no such effect, as suggested by a comparison of the corresponding $\mathrm{C} 6-\mathrm{N}(1.37 \AA$ in motor $2 \mathrm{c})$ and $\mathrm{C} 3-\mathrm{N}(1.47 \AA$ in motor $3 \mathbf{c}$ ) bond lengths. In this way, the stator of motor $2 \mathbf{c}$ is made flatter and steric interactions are increased. 
Finally, having presented three systems (motors $\mathbf{2 a - 2 c}$ ) with rate-determining thermal barriers of such magnitudes that high rotational frequencies seem feasible, it remains to investigate through, e.g., non-adiabatic molecular dynamics simulations $[53,63-65,82]$ whether the photochemical steps of these systems sustain rotary motion and proceed efficiently. Although such simulations are beyond the scope of this work, preliminary calculations presented in Fig. S1 and Table S5 of the ESM do suggest that the photochemical steps are favorable in this regard. First, from Fig. S1, it can be seen that the preferred direction of photoinduced torsional motion along the $\alpha$ (C9a-C9-C1'-C9'a, see Scheme 3) coordinate is the same for the light-absorbing anti-( $M)$-stable- $E$ and anti-(M)stable- $Z$ isomers of motors $\mathbf{2 a}-\mathbf{2 c}$. This indicates that the $E \rightarrow$ $Z$ and $Z \rightarrow E$ photoisomerizations of these systems occur in a unidirectional fashion and produce rotary motion. Second, Table S5 shows that the thermal isomerizations of all motors in this work are markedly exergonic. This means that the photoisomerized species are removed from the photoequilibria, which limits the negative impact on the unidirectional rotary motion from photoinduced back rotations.

\section{Conclusions}

We have used DFT methods to investigate whether the thermal isomerizations of a rotary molecular motor estimated to achieve $\mathrm{MHz}$ rotational frequencies under suitable irradiation conditions (motor 1a [28]), can be accelerated by introducing stator substituents with either electron-donating or electronwithdrawing character in conjugation with the central olefinic bond. Specifically, using not only motor $\mathbf{1 a}$ as reference system but also two motors (motors $\mathbf{1 b}$ and $\mathbf{1 c}$ ) obtained by replacing the rotator methyl substituent of motor $1 \mathrm{a}$ with a nitro (motor 1b) or methoxy (motor 1c) group, we have investigated if the thermal isomerizations of these three motors can be accelerated by introducing electron-donating methoxy and dimethylamino (yielding motors $\mathbf{2 a - 2 c}$ ) or electronwithdrawing nitro and cyano (yielding motors $\mathbf{3 a}-\mathbf{3 c}$ ) groups at the $\mathrm{C} 3$ and $\mathrm{C} 6$ positions of the thioxanthene stator.

Through the calculations, the same three-step mechanism previously documented for the thermal syn- $(P)$-unstable- $Z \rightarrow$ anti-( $(M)$-stable- $Z$ and syn- $(P)$-unstable- $E \rightarrow \operatorname{anti-}(M)$-stable- $E$ isomerizations of motor 1a [42] is also implicated for all the other motors studied. Furthermore, while it is found that the electron-withdrawing stator substituents of motors $\mathbf{3 a}-\mathbf{3 c}$ exert no influence on the thermal isomerization rates, it is demonstrated that the free-energy barriers of the third step that is rate-determining for reference motors $\mathbf{1 a}-\mathbf{1 c}$ can be lowered by up to $18 \mathrm{~kJ} \mathrm{~mol}^{-1}$ through the inclusion of electrondonating stator substituents in motors $\mathbf{2 a}-\mathbf{2} \mathbf{c}$, without a corresponding increase in the barriers of the first and second steps. As a result, for motors $\mathbf{2} \mathbf{a}$ and $\mathbf{2} \mathbf{b}$, the rate-determining barriers are $12-16 \mathrm{~kJ} \mathrm{~mol}^{-1}$ smaller than those of motors $\mathbf{1 a}$ and $\mathbf{1 b}$. Accordingly, motors $\mathbf{2 a}$ and $\mathbf{2 b}$ appear promising candidates to substantially improve the rotational frequencies of overcrowded alkene-based molecular motors.

For motor $\mathbf{2 c}$, in turn, the calculated rate-determining barrier $\left(25 \mathrm{~kJ} \mathrm{~mol}^{-1}\right)$ is comparably small to those of motors $\mathbf{2 a}$ $\left(31 \mathrm{~kJ} \mathrm{~mol}^{-1}\right)$ and $\mathbf{2 b}\left(23 \mathrm{~kJ} \mathrm{~mol}^{-1}\right)$, which suggests that this system is also a potential fast-rotating motor. However, relative to its reference motor $\mathbf{1 c}$, which is already accelerated by some $15 \mathrm{~kJ} \mathrm{~mol}^{-1}$ over motor 1a by carrying a stereogenic rotator substituent with optimal steric bulkiness [42], the inclusion of electron-donating stator substituents in motor $\mathbf{2 c}$ offers no further lowering of the rate-determining barrier.

Finally, attempting to understand why electron-donating but not electron-withdrawing stator substituents are able to exert a catalytic effect, it is found that the former groups ease the steric requirements to pass through the critical third and final step of the isomerizations. In closing, we are thus proposing a strategy for improving, on steric grounds, the performance of overcrowded alkene-based molecular motors without actually changing the steric bulkiness of the groups contributing to the interactions in question. We believe that this proposal holds new promise for the future development of these motors.

Acknowledgments We acknowledge financial support from Linköping University, the Swedish Research Council (grant 621-2011-4353), the Olle Engkvist Foundation and the Carl Trygger Foundation, as well as grants of computing time at the National Supercomputer Centre (NSC) in Linköping.

\section{Compliance with ethical standards}

Conflict of interest The authors declare no competing financial interest.

Open Access This article is distributed under the terms of the Creative Commons Attribution 4.0 International License (http:// creativecommons.org/licenses/by/4.0/), which permits unrestricted use, distribution, and reproduction in any medium, provided you give appropriate credit to the original author(s) and the source, provide a link to the Creative Commons license, and indicate if changes were made.

\section{References}

1. Kinbara K, Aida T (2005) Toward intelligent molecular machines: directed motions of biological and artificial molecules and assemblies. Chem Rev 105:1377-1400. doi:10.1021/cr030071r

2. Browne WR, Feringa BL (2006) Making molecular machines work. Nat Nanotechnol 1:25-35. doi:10.1038/nnano.2006.45

3. Kay ER, Leigh DA, Zerbetto F (2007) Synthetic molecular motors and mechanical machines. Angew Chem Int Ed 46:72-191. doi:10.1002/anie.200504313

4. Balzani V, Credi A, Venturi M (2009) Light powered molecular machines. Chem Soc Rev 38:1542-1550. doi:10.1039/b806328c 
5. Leigh DA, Wong JKY, Dehez F, Zerbetto F (2003) Unidirectional rotation in a mechanically interlocked molecular rotor. Nature 424 : 174-179. doi:10.1038/nature01758

6. Kottas GS, Clarke LI, Horinek D, Michl J (2005) Artificial molecular rotors. Chem Rev 105:1281-1376. doi:10.1021/cr0300993

7. Feringa BL (2007) The art of building small: from molecular switches to molecular motors. J Org Chem 72:6635-6652. doi:10.1021/jo070394d

8. Michl J, Sykes ECH (2009) Molecular rotors and motors: recent advances and future challenges. ACS Nano 3:1042-1048. doi:10.1021/nn900411n

9. Panman MR, Bodis P, Shaw DJ, Bakker BH, Newton AC, Kay ER, Brouwer AM, Jan Buma W, Leigh DA, Woutersen S (2010) Operation mechanism of a molecular machine revealed using time-resolved vibrational spectroscopy. Science 328:1255-1258. doi:10.1126/science.1187967

10. Kudernac T, Ruangsupapichat N, Parschau M, Maciá B, Katsonis N, Harutyunyan SR, Ernst KH, Feringa BL (2011) Electrically driven directional motion of a four-wheeled molecule on a metal surface. Nature 479:208-211. doi:10.1038/nature10587

11. Sykes ECH (2012) Electric nanocar equipped with four-wheel drive gets taken for its first spin. Angew Chem Int Ed 51:4277-4278. doi:10.1002/anie.201108783

12. Pathem BK, Claridge SA, Zheng YB, Weiss PS (2013) Molecular switches and motors on surfaces. Annu Rev Phys Chem 64:605630. doi:10.1146/annurev-physchem-040412-110045

13. Greb L, Lehn JM (2014) Light-driven molecular motors: imines as four-step or two-step unidirectional rotors. J Am Chem Soc 136: 13114-13117. doi:10.1021/ja506034n

14. Guentner M, Schildhauer M, Thumser S, Mayer P, Stephenson D, Mayer PJ, Dube H (2015) Sunlight powered KHz rotation of a hemithioindigo-based molecular motor. Nat Commun 6:8406. doi:10.1038/ncomms9406

15. Cordes T, Elsner C, Herzog TT, Hoppmann C, Schadendorf T, Summerer W, Rück-Braun K, Zinth W (2009) Ultrafast hemithioindigo-based peptide-switches. Chem Phys 358:103-110. doi:10.1016/j.chemphys.2008.12.027

16. Perrier A, Maurel F, Jacquemin D (2012) Single molecule multiphotochromism with diarylethenes. Acc Chem Res 45: 1173-1182. doi:10.1021/ar200214k

17. Bléger D, Hecht S (2015) Visible-light-activated molecular switches. Angew Chem Int Ed 54:11338-11349. doi:10.1002 /anie. 2015000628

18. Harada N, Koumura N, Feringa BL (1997) Chemistry of unique chiral olefins. 3. Synthesis and absolute stereochemistry of transand cis-1, 1',2,2',3,3',4,4'-octahyrdo-3,3'-dimethyl-4,4'biphenanthrylidenes. J Am Chem Soc 119:7256-7264. doi:10.1021/ja970669e

19. Koumura N, Zijlstra RWJ, van Delden RA, Harada N, Feringa BL (1999) Light-driven monodirectional molecular rotor. Nature 401: 152-155. doi:10.1038/43646

20. Feringa BL, Koumura N, van Delden RA, ter Wiel MKJ (2002) Light-driven molecular switches and motors. Appl Phys A 75:301308. doi:10.1007/s003390201338

21. Koumura N, Geertsema EM, van Gelder MB, Meetsma A, Feringa BL (2002) Second-generation light-driven molecular motors. Unidirectional rotation controlled by a single stereogenic center with near-perfect photoequilibria and acceleration of the speed of rotation by structural modification. J Am Chem Soc 124:50375051. doi:10.1021/ja012499i

22. ter Wiel MKJ, van Delden RA, Meetsma A, Feringa BL (2003) Increased speed of rotation for the smallest light-driven molecular motor. J Am Chem Soc 125:15076-15086. doi:10.1021/ja036782o

23. van Delden RA, Koumura N, Schoevaars A, Meetsma A, Feringa BL (2003) A donor-acceptor substituted molecular motor: unidirectional rotation driven by visible light. Org Biomol Chem 1:33-35. doi:10.1039/b209378b

24. Pijper D, van Delden RA, Meetsma A, Feringa BL (2005) Acceleration of a nanomotor: electronic control of the rotary speed of a light-driven molecular rotor. J Am Chem Soc 127:1761217613. doi:10.1021/ja054499e

25. ter Wiel MKJ, van Delden RA, Meetsma A, Feringa BL (2005) Light-driven molecular motors: stepwise thermal helix inversion during unidirectional rotation of sterically overcrowded biphenanthrylidenes. J Am Chem Soc 127:14208-14222. doi:10.1021/ja052201e

26. Vicario J, Walko M, Meetsma A, Feringa BL (2006) Fine tuning of the rotary motion by structural modification in light-driven unidirectional molecular motors. J Am Chem Soc 128:5127-5135. doi:10.1021/ja058303m

27. Pollard MM, Klok M, Pijper D, Feringa BL (2007) Rate acceleration of light-driven rotary molecular motors. Adv Funct Mater 17: 718-729. doi:10.1002/adfm.200601025

28. Klok M, Boyle N, Pryce MT, Meetsma A, Browne WR, Feringa BL (2008) $\mathrm{MHz}$ unidirectional rotation of molecular rotary motors. J Am Chem Soc 130:10484-10485. doi:10.1021/ja8037245

29. Klok M, Walko M, Geertsema EM, Ruangsupapichat N, Kistemaker JCM, Meetsma A, Feringa BL (2008) New mechanistic insight in the thermal helix inversion of second-generation molecular motors. Chem Eur J 14:11183-11193. doi:10.1002 /chem.200800969

30. Pollard MM, Meetsma A, Feringa BL (2008) A redesign of lightdriven rotary molecular motors. Org Biomol Chem 6:507-512. doi:10.1039/b715652a

31. Pollard MM, Wesenhagen PV, Pijper D, Feringa BL (2008) On the effect of donor and acceptor substituents on the behaviour of lightdriven rotary molecular motors. Org Biomol Chem 6:1605-1612. doi:10.1039/b718294e

32. Landaluce TF, London G, Pollard MM, Rudolf P, Feringa BL (2010) Rotary molecular motors: a large increase in speed through a small change in design. J Org Chem 75:5323-5325. doi:10.1021 /jo1006976

33. Kulago AA, Mes EM, Klok M, Meetsma A, Brouwer AM, Feringa BL (2010) Ultrafast light-driven nanomotors based on an acridane stator. J Org Chem 75:666-679. doi:10.1021/jo902207x

34. Ruangsupapichat N, Pollard MM, Harutyunyan SR, Feringa BL (2011) Reversing the direction in a light-driven rotary molecular motor. Nat Chem 3:53-60. doi:10.1038/nchem.872

35. Vachon J, Carroll GT, Pollard MM, Mes EM, Brouwer AM, Feringa BL (2014) An ultrafast surface-bound photo-active molecular motor. Photochem Photobiol Sci 13:241-246. doi:10.1039/c3 pp50208b

36. Bauer J, Hou L, Kistemaker JCM, Feringa BL (2014) Tuning the rotation rate of light-driven molecular motors. J Org Chem 79: 4446-4455. doi:10.1021/jo500411z

37. Conyard J, Cnossen A, Browne WR, Feringa BL, Meech SR (2014) Chemically optimizing operational efficiency of molecular rotary motors. J Am Chem Soc 136:9692-9700. doi:10.1021/ja5041368

38. van Delden RA, ter Wiel MKJ, Pollard MM, Vicario J, Koumura N, Feringa BL (2005) Unidirectional molecular motors on a gold surface. Nature 437:1337-1340. doi:10.1038/nature04127

39. Katsonis N, Lubomska M, Pollard MM, Feringa BL, Rudolf $\mathrm{P}$ (2007) Synthetic light-activated molecular switches and motors on surfaces. Prog Surf Sci 82:407-434. doi:10.1016/j. progsurf.2007.03.011

40. Vacek J, Michl J (2007) Artificial surface-mounted molecular rotors: molecular dynamics simulations. Adv Funct Mater 17:730 739. doi:10.1002/adfm.200601225

41. London G, Carroll GT, Feringa BL (2013) Silanization of quartz, silicon and mica surfaces with light-driven molecular motors: 
construction of surface-bound photo-active nanolayers. Org Biomol Chem 42:3477-3483. doi:10.1039/C3OB40276B

42. Oruganti B, Fang C, Durbeej B (2015) Computational design of faster rotating second-generation light-driven molecular motors by control of steric effects. Phys Chem Chem Phys 17:21740-21751. doi: $10.1039 / \mathrm{c} 5 \mathrm{cp} 02303 \mathrm{c}$

43. Eelkema R, Pollard MM, Vicario J, Katsonis N, Ramon BS, Bastiaansen CWM, Broer DJ, Feringa BL (2006) Nanomotor rotates microscale objects. Nature 440:163. doi:10.1038/440163a

44. Chiang PT, Mielke J, Godoy J, Guerrero JM, Alemany LB, Villagómez CJ, Saywell A, Grill L, Tour JM (2012) Toward a light-driven motorized nanocar: synthesis and initial imaging of single molecules. ACS Nano 6:592-597. doi:10.1021/nn203969b

45. Chen J, Kistemaker JCM, Robertus J, Feringa BL (2014) Molecular stirrers in action. J Am Chem Soc 136:14924-14932. doi:10.1021 /ja507711h

46. Gavvala K, Satpathi S, Hazra P (2015) Ultrafast dynamics of a molecular rotor in chemical and biological nano-cavities. RSC Adv 5:72793-72800. doi:10.1039/c5ra13298c

47. Klok M, Browne WR, Feringa BL (2009) Kinetic analysis of the rotation rate of light-driven unidirectional molecular motors. Phys Chem Chem Phys 11:9124-9131. doi:10.1039/b906611j

48. Augulis R, Klok M, Feringa BL, van Loosdrecht PHM (2009) Light-driven rotary moleular motors: an ultrafast optical study. Phys Status Solidi C 6:181-184. doi:10.1002/pssc.200879808

49. Conyard J, Addison K, Heisler IA, Cnossen A, Browne WR, Feringa BL, Meech SR (2012) Ultrafast dynamics in the power stroke of a molecular rotary motor. Nat Chem 4:547-551. doi:10.1038/nchem.1343

50. Grimm S, Bräuchle C, Frank I (2005) Light-driven unidirectional rotation in a molecule: ROKS simulation. ChemPhysChem 6: 1943-1947. doi:10.1002/cphc.200400529

51. Kazaryan A, Filatov M (2009) Density functional study of the ground and excited state potential energy surfaces of a lightdriven rotary molecular motor $\left(3 \mathrm{R}, 3^{\prime} \mathrm{R}\right)-(\mathrm{P}, \mathrm{P})$-trans-1,1',2,2',3,3', 4,4'-octahydro-3,3',-dimethyl-4,4'-biphenathrylidene. J Phys Chem A 113:11630-11634. doi:10.1021/jp902389j

52. Kazaryan K, Kistemaker JCM, Schäfer LV, Browne WR, Feringa BL, Filatov M (2010) Understanding the dynamics behind the photoisomerization of a light-driven fluorene molecular rotary motor. J Phys Chem A 114:5058-5067. doi:10.1021/jp100609m

53. Kazaryan A, Lan Z, Schäfer LV, Thiel W, Filatov M (2011) Surface hopping excited-state dynamics of the photoisomerization of a light-driven fluorene molecular rotary motor. J Chem Theory Comput 7:2189-2199. doi:10.1021/ct200199w

54. Liu F, Morokuma K (2012) Computational study on the working mechansim of a stilbene light-driven molecular rotary motor: sloped minimal energy path and unidirectional nonadiabatic photoisomerization. J Am Chem Soc 134:4864-4876. doi:10.1021/ja211441n

55. Filatov M, Olivucci M (2014) Designing conical intersections for light-driven single molecule rotary motors: from precessional to axial motion. J Org Chem 79:3587-3600. doi:10.1021/jo5004289

56. Zijlstra RWJ, Jager WF, de Lange B, van Duijnen PT, Feringa BL, Goto H, Saito A, Koumura N, Harada N (1999) Chemistry of unique chiral olefns. 4. Theoretical studies of the racemization

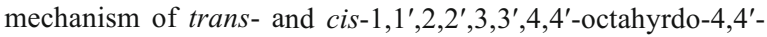
biphenanthrylidenes. J Org Chem 64:1667-1674. doi:10.1021 /jo982381t

57. Pérez-Hernández G, González L (2010) Mechanistic insight into light-driven molecular rotors: a conformational search in chiral overcrowded alkenes by a pseudo-random approach. Phys Chem Chem Phys 12:12279-12289. doi:10.1039/c0cp00324g

58. Cnossen A, Kistemaker JCM, Kojima T, Feringa BL (2014) Structural dynamics of overcrowded alkene-based molecular motors during thermal isomerization. J Org Chem 79:927-935. doi:10.1021/jo402301j

59. Assmann M, Pérez-Hernández G, González L (2010) On the lightdriven isomerization of a model asymmetric molecular rotor: conformations and conical intersections of 2-cyclopentylidene-tetrahydrofuran. J Phys Chem A 114:9342-9348. doi:10.1021/jp104898t

60. Assmann M, Sanz CS, Pérez-Hernández G, Worth GA, González L (2010) Excited state dynamics of a model asymmetric molecular rotor: a five-dimensional study on 2-cyclopentylidene-tetrahydrofuran. Chem Phys 377:86-95. doi:10.1016/j. chemphys.2010.08.019

61. Amatatsu Y (2011) Theoretical design of a light-driven molecular rotary motor with low energy helical inversion: 9-(5-methyl-2-phenyl-2-cyclopenten-1-ylidene)-9H-fluorene. J Phys Chem A 115: 13611-13618. doi:10.1021/jp207238n

62. Amatatsu Y (2012) Theoretical design of a fluorene-based lightdriven molecular rotary motor with constant rotation. J Phys Chem A 116:10182-10193. doi:10.1021/jp306414p

63. García-Iriepa C, Marazzi M, Zapata F, Valentini A, Sampedro D, Frutos LM (2013) Chiral hydrogen bond environment providing unidirectional rotation in photoactive molecular motors. J Phys Chem Lett 4:1389-1396. doi:10.1021/jz302152v

64. Marchand G, Eng J, Schapiro I, Valentini A, Frutos LM, Pieri E, Olivucci M, Léonard J, Gindensperger E (2015) Directionality of double-bond photoisomerization dynamics induced by a single stereogenic center. J Phys Chem Lett 6:599-604. doi:10.1021 /jz502644h

65. Nikiforov A, Gamez JA, Thiel W, Filatov M (2016) Computational design of a family of light-driven rotary molecular motors with improved quantum efficiency. J Phys Chem Lett 7:105-110. doi:10.1021/acs.jpclett.5b02575

66. Fang C, Oruganti B, Durbeej B (2014) Computational study of the working mechanism and rate acceleration of overcrowded alkenebased light-driven rotary molecular motors. RSC Adv 4:10240 10251. doi:10.1039/c3ra46880a

67. Lee C, Yang W, Parr RG (1988) Development of the Colle-Salvetti correlation-energy formula into a functional of the electron density. Phys Rev B 37:785-789. doi:10.1103/PhysRevB.37.785

68. Becke AD (1993) Density-functional thermochemistry. III. The role of exact exchange. J Chem Phys 98:5648-5652. doi:10.1063 $/ 1.464913$

69. Perdew JP, Burke K, Ernzerhof M (1996) Generalized gradient approximation made simple. Phys Rev Lett 77:3865-3868. doi:10.1103/PhysRevLett.77.3865

70. Ernzerhof M, Scuseria GE (1999) Assessment of the PerdewBurke-Ernzerhof exchange-correlation functional. J Chem Phys 110:5029-5036. doi:10.1063/1.478401

71. Zhao Y, Truhlar DG (2006) Density functional for spectroscopy: no long-range self-interaction error, good performance for Rydberg and charge-transfer states, and better performance on average than B3LYP for ground states. J Phys Chem A 110:13126-13130. doi:10.1021/jp066479k

72. Zhao Y, Truhlar DG (2008) The M06 suite of density functionals for maingroup thermochemistry, thermochemical kinetics, noncovalent interactions, excited states, and transition elements: two new functionals and systematic testing of four M06-class functionals and 12 other functionals. Theor Chem Accounts 120:215241. doi:10.1007/s00214-007-0310-x

73. Chai JD, Head-Gordon M (2008) Long-range corrected hybrid density functionals with damped atom-atom dispersion corrections. Phys Chem Chem Phys 10:6615-6620. doi:10.1039/b810189b

74. Yanai T, Tew DP, Handy NC (2004) A new hybrid exchangecorrelation functional using the coulomb-attenuating method (CAM-B3LYP). Chem Phys Lett 393:51-57. doi:10.1016/j. cplett.2004.06.011 
75. Marenich AV, Cramer CJ, Truhlar DG (2009) Universal solvation model based on solute electron density and on a continuum model of the solvent defined by the bulk dielectric constant and atomic surface tensions. J Phys Chem B 113:6378-6396. doi:10.1021 /jp810292n

76. Grimme S (2004) Accurate description of van der Waals complexes by density functional theory including empirical corrections. J Comput Chem 25:1463-1473. doi:10.1002 /jcc.20078

77. Antony J, Grimme S (2006) Density functional theory including dispersion corrections for intermolecular interactions in a large benchmark set of biologically relevant molecules. Phys Chem Chem Phys 8:5287-5293. doi:10.1039 /b612585a

78. Schenker S, Schneider C, Tsogoeva SB, Clark T (2011) Assessment of popular DFT and semiempirical molecular orbital techniques for calculating relative transition state energies and kinetic product distributions in enantioselective organocatalytic reactions. J Chem Theory Comput 7:3586-3595. doi:10.1021/ct2002013

79. Hratchian HP, Schlegel HB (2004) Accurate reaction paths using a Hessian based predictor-corrector integrator. J Chem Phys 120: 9918-9924. doi:10.1063/1.1724823
80. Frisch MJ, Trucks GW, Schlegel HB, Scuseria GE, Robb MA, Cheeseman JR, Scalmani G, Barone V, Mennucci B, Petersson GA, Nakatsuji H, Caricato M, Li X, Hratchian HP, Izmaylov AF, Bloino J, Zheng G, Sonnenberg JL, Hada M, Ehara M, Toyota K, Fukuda R, Hasegawa J, Ishida M, Nakajima T, Honda Y, Kitao O, Nakai H, Vreven T, Montgomery JA Jr, Peralta JE, Ogliaro F, Bearpark M, Heyd JJ, Brothers E, Kudin KN, Staroverov VN, Kobayashi R, Normand J, Raghavachari K, Rendell A, Burant JC, Iyengar SS, Tomasi J, Cossi M, Rega N, Millam JM, Klene M, Knox JE, Cross JB, Bakken V, Adamo C, Jaramillo J, Gomperts R, Stratmann RE, Yazyev O, Austin AJ, Cammi R, Pomelli C, Ochterski JW, Martin RL, Morokuma K, Zakrzewski VG, Voth GA, Salvador P, Dannenberg JJ, Dapprich S, Daniels AD, Farkas Ö, Foresman JB, Ortiz JV, Cioslowski J, Fox DJ (2009) Gaussian 09, revision D.01. Gaussian Inc, Wallingford

81. Bondi A (1964) van der Waals volumes and radii. J Phys Chem 68: 441-451. doi:10.1021/j100785a001

82. Sellner B, Barbatti M, Müller T, Domcke W, Lischka H (2013) Ultrafast non-adiabatic dynamics of ethylene including Rydberg states. Mol Phys 111:2439-2450. doi:10.1080 /00268976.2013.813590 